\title{
TOWARDS HAPPINESS: EXPERIENCES OF WORK-ROLE FIT, MEANINGFULNESS AND WORK ENGAGEMENT OF INDUSTRIAL/ORGANISATIONAL PSYCHOLOGISTS IN SOUTH Africa
}

\author{
Authors: \\ Llewellyn E. van Zy $1^{1}$ \\ Elmari Deacon ${ }^{1}$ \\ Sebastiaan Rothmann ${ }^{1}$

\section{Affiliations: \\ ${ }^{1}$ School of Behavioural Sciences, North-West \\ University, Vanderbijlpark, South Africa}

\section{Correspondence to:}

Sebastiaan Rothmann

email:

ian@ianrothmann.com

Postal address:

PO Box 11789, Klein

Windhoek, Namibia

\section{Keywords:}

engagement; happiness; industrial/organisational psychologists; meaning; work-role fit

\section{Dates:}

Received: 22 Jan. 2010 Accepted: 25 June 2010 Published: 04 Oct. 2010

How to cite this article: Van Zyl, L.E., Deacon,

E., \& Rothmann, S.

Towards happiness:

Experiences of work-role fit, meaningfulness and work engagement of industrial/organisational psychologists in South Africa. SA Journal of Industrial Psychology/SA Tydskrif vir Bedryfsielkunde, 36(1), Art. \#890, 10 pages.

DOI: 10.4102/sajip.v36i1.890

This article is available at: http://www.sajip.co.za

(C) 2010. The Authors. Licensee: OpenJournals Publishing. This work is licensed under the Creative Commons Attribution License.

\begin{abstract}
Orientation: The work of industrial/organisational (I/O) psychologists presents an interesting and relevant context for studying meaning and engagement as components of happiness.

Research purpose: The aim of this study was to determine how I/O psychologists experience the meaning of their work and to investigate the relationships between their experiences of work-role fit, meaning of work, psychological meaningfulness and work engagement, utilising the happiness framework proposed by Seligman (2002).
\end{abstract}

Motivation for the study: I/O psychologists spend more than $88 \%$ of their working day with people, and they are primary role models for happiness in the workplace. Information about their work engagement and experiences of meaning is therefore needed.

Research design, approach and method: A survey design was used. A convenience sample $(n=$ 106) was taken of I/O psychologists in South Africa. A biographical questionnaire, the Work-Role Fit Scale, the Work-Life Questionnaire, the Psychological Meaningfulness Scale, the Work Engagement Scale and a survey measuring the actual and desired time spent on six broad categories of work were administered.

Main findings: Work-role fit predicted psychological meaningfulness and work engagement. The calling orientation to work predicted both psychological meaningfulness and work engagement. Work-role fit mediated the relationship between the meaning of work and psychological meaningfulness. Work-role fit partially mediated the relationship between a calling orientation to work and work engagement.

Practical implications: A calling orientation to work should be fostered in I/O psychologists because it contributes to experiences of work-role fit, psychological meaningfulness and work engagement.

Contribution/value-add: The results of this study contribute to scientific knowledge about workrole fit, engagement and meaning as components of happiness of I/O psychologists.

\section{INTRODUCTION}

Happiness is an elusive concept yet a 'buzz-word' in modern society (Seligman, 2002). The concept has been the subject of much scrutiny and debate in recent years (Peterson, Park, Hall \& Seligman, 2009; Seligman, 2002; Sirgy \& Wu, 2009). Happiness refers to the experience of a sense of joy, satisfaction and positive well-being, combined with a sense that one's life is good, meaningful and worthwhile (Seligman, 2002). It is estimated that more than half the world's population is unhappy. These individuals lack enthusiasm and are not actively and productively engaged with the world (Ryan \& Deci, 2001; Seligman, 2002, 2008). Research shows that the presence of happiness manifests in various positive results, including superior attention span, longevity, recovery from illnesses and protection against the onset of physical diseases and pathology (Seligman, 2008). While happiness is an important concept both for individuals and organisations, scientific information is needed about happiness and the components thereof within the South African context.

Peterson, Park and Seligman (2005) propose an integrated model for happiness flowing from the hedonic and eudaimonic approaches. The hedonic approach focuses on pleasures of the mind and the body and on the avoidance of pain. Eudaimonia is concerned with a deeper level of perceived happiness (Ryan \& Deci, 2001). Peterson et al. (2005) suggest three routes to happiness, namely pleasure (the pleasant life), meaningfulness (the meaningful life) and engagement (the good life). Peterson et al. (2005) found that these routes to happiness are discernible and compatible and could be pursued simultaneously. However, engagement and meaning as routes to happiness seem more under deliberate control of individuals than pleasure (Seligman, Parks \& Steen, 2004). According to Seligman (2002), interventions that target only the pleasure of individuals (to promote happiness) will be short lived and ineffective because individuals have a genetic set point for the experience of pleasure.

Individuals spend more than a third of their lives engaged in work-related activities (Wrzesniewski, McCauley, Rozin \& Schwartz, 1997). Since work is central to their existence, individuals tend to build their identities around their work (Meyers, 2007). Work is an important context to engage individuals in goal-directed activities and to provide meaning (Cameron, Dutton \& Quinn, 2003). Work-role fit, meaning of work, psychological meaningfulness and work engagement have recently become important research topics (Dik \& Duffy, 2008; May, Gilson \& Harter, 2004; Olivier \& Rothmann, 2007; Schaufeli \& Bakker, 2004; Wrzesniewski \& Tosti, 2005). 
The perceived fit between individuals' self-concepts and their roles within the organisation (work-role fit) results in the experience of meaningfulness and engagement (May et al., 2004 Olivier \& Rothmann, 2007). Work roles and activities that are aligned with individuals' self-concepts should be associated with more meaningful work experiences (May et al., 2004; Seligman, 2002). Participating in activities that are congruent with an individual's values (Waterman, 1993) and/or signature strengths (Peterson \& Seligman, 2004) contributes to the experience of psychological meaningfulness and engagement in work (May et al., 2004)

Meaningfulness manifests in, (1) the meaning of work (Bellah, Madsen, Sullivan, Swidler \& Tipton, 1985; Wrzesniewski et al., 1997) and (2) psychological meaningfulness (May et al., 2004). Bellah et al. (1985) define the meaning of work as the level of general significance that the subjective experience of working has in the life of individuals at a given time stamp. Bellah et al. (1985) cluster this subjective experience into three broad categories, namely work as a job, work as a career and work as a calling. Psychological meaningfulness is defined as the the value of a work goal or purpose, judged in relation to an individual's own ideals or standards' (May et al., 2004, p. 14). In South Africa, studies pertaining to work-role fit and meaningfulness, in both its facets, namely, (1) the meaning of work (Carvalho, 2005) and (2) psychological meaningfulness (Olivier \& Rothmann, 2007), are limited. The meaning attached to work as well as experiences of psychological meaningfulness lead to positive work-related outcomes (see Pratt \& Ashforth, 2003; Wrzesniewski \& Dutton, 2001) and specifically engagement (May et al., 2004; Olivier \& Rothmann, 2007)

Work engagement is an important ideal within the current economic situation in South Africa. May et al. (2004) define work engagement as an extension of individuals' selves to a work role whereby they employ and express themselves physically, cognitively and emotionally during role performance. In a South African context, no studies have been found relating to industrial/organisational (I/O) psychologists' level of engagement.

The work of I/O psychologists presents an interesting context for studying work-role fit, meaningfulness and engagement. There are three reasons for this. Firstly, I/O psychologists are trapped between their roles as traditional human resource (HR) practitioners and psychologists (Barnard \& Fourie, 2007; Benjamin \& Louw-Potgieter, 2008). I/O psychologists might spend less time on desired activities (e.g. counselling, mentoring and coaching), consequently increasing the gap between their work role and their self-concept. This could result in disengagement (May et al., 2004; Olivier \& Rothmann, 2007). Secondly, Bellah et al. (1985) argue that the effect of the meaning of work is clearly visible in social occupations. These occupations refer to careers in which individuals are constantly interacting with various social systems within an organisation (Bellah et al., 1985). Thirdly, Cameron et al. (2003) argue that I/O psychologists are the primary role models for change, happiness and hope within the organisation. I/O psychologists are perceived to be leaders within the organisation (Barnard \& Fourie, 2007). If the I/O psychologist is not happy (i.e. not experiencing psychological meaningfulness and engagement), it could spill over into the other employees (Meyers, 2007).

Very little information exists regarding the effects of meaning of work and work-role fit on I/O psychologists' experiences of psychological meaningfulness in their work and the effects thereof on their engagement. Scientific information about these issues can be of great value in the development of the I/O psychology profession and in the implementation of programmes to address the happiness of I/O psychologists. As happiness facilitators and change agents, I/O psychologists need to show happiness (in terms of meaningfulness and engagement) in order to ensure that it spills over into the other employees.
The objective of this study was to investigate the relationships between work-role fit, meaningfulness (meaning of work and psychological meaningfulness) and work engagement as the pathway towards happiness of I/O psychologists in South Africa.

\section{Work-role fit, meaning and work engagement}

Work-role fit is defined as the perceived fit between an individual's self-concept and his or her role (May et al., 2004). Close proximity between an individual's self-concept and his or her work role induces psychological meaningfulness, since the person is able to express his or her beliefs, values and principles openly (Kahn, 1990; May et al., 2004). Research suggests that individuals will seek out work roles that allow them to express their true selves (May et al., 2004; Olivier \& Rothmann, 2007). Authenticity is facilitated through the freedom to express creativity and uniqueness (LeBon, 2001). Individuals experiencing high levels of work-role fit perceive their jobs to be callings and are willing to go beyond occupational restraints to accomplish tasks (Dik \& Duffy, 2008). Experiencing low levels of work-role fit will lead to job recrafting in terms of which individuals reshape their work activities in order to derive more meaning (Wrzesniewski, 2003). Wrzesniewski and Dutton (2001) suggest that these individuals transform cognitive processes, work activities and/or relational boundaries in order to form relationships and shape relationships with others at work.

Job recrafting is used in order to reshape the working world, to ensure a closer work-role fit (Berg, Dutton \& Wrzesniewski, 2008). The closer the relationship between the self and the work role, the more meaning and engagement are derived (Berg et al., 2008). The process of crafting one's job to close the gap between the self and the work role is a continuous process (Berg et al., 2008; Wrzesniewski \& Dutton, 2001). Research has shown that individuals are continuously searching for meaningful work experiences, which is facilitated through job recrafting (Berg et al., 2008).

The origin of the concept of meaning can be traced back to the work of Victor Frankl (Bellah et al., 1985; Frankl, 1988; Wrzesniewski, Dutton \& Debebe, 2003). Meaningfulness consists of, (1) the meaning of work (Wrzesniewski et al., 1997) and (2) psychological meaningfulness (Kahn, 1990; May et al., 2004; Spreitzer, 1995). Bellah et al. (1985) define the meaning of work as the general level of importance an individual attaches to the subjective experience of work at a given time stamp. This general level of importance of work in the life of an individual manifests in three distinct dimensions: the individual views work either as a job, a career or a calling (Bellah et al., 1985; Wrzesniewski et al., 1997).

Individuals who view work as a job are ensnared by the allure of the material rewards they receive from work. These individuals view work as a means to an end. Little satisfaction is derived from work-related activities. However, the material rewards gained are utilised to acquire resources needed to express ambitions outside of an occupational context (Parry, 2006; Wrzesniewski et al., 1997; Wrzesniewski et al., 2003).

As opposed to this, a person who views work as a career is concerned with occupational advancement rather than just monetary rewards (Parry, 2006; Peterson et al., 2009; Wrzesniewski et al., 1997). Here meaning is derived from the increased level of perceived power, influence and higher social status that advancement holds. Increased power and social status manifest in increased self-esteem (Wrzesniewski et al., 1997). Satisfaction and engagement depend on continuous advancement (Peterson et al., 2009). Frustration, disengagement and dissatisfaction occur when advancement slows (Lopper, 2007; Wrzesniewski et al., 1997). Research suggests that individuals who view work as a career are happier than those who view work as a job but less so than those who view work as a calling (Dik \& Duffy, 2008; Peterson et al., 2009). 
Viewing work as a calling is an end in itself (Peterson et al., 2009; Wrzesniewski et al., 1997; Wrzesniewski et al., 2003). Viewing work as a calling implies a feeling that one was placed on earth to engage in these specific work-related tasks (Parry, 2006). Those who view work as a calling engage in work as a result of the fulfilment they derive from engaging in these activities as opposed to financial gains (work as a job) and career advancement (work as a career) (Wrzesniewski et al., 1997). These individuals perceive their work and not remuneration, to be their purpose in life (Bellah et al., 1985).

Perceiving work as a calling has benefits for the individual, the group and the organisation, including zest, life satisfaction and organisational commitment (Cameron et al., 2003; Peterson et al., 2009; Wrzesniewski et al., 2003). Individuals within similar occupations, tenures and remuneration can view work differently. However, individuals within social occupations (e.g. counsellors, ministers, priests, social workers and psychologists) are more likely to experience their work as a calling rather than as a career or a job (Wrzesniewski et al., 1997).

The meaning of work is clearly visible in occupations in which individuals are constantly interacting with various social systems, since the need for socialisation, influence and affiliation largely contributes to the experience of meaning of work (Bellah et al., 1985). Registered I/O psychologists spend $88 \%$ of their time interacting with various social systems within an organisational context (Benjamin \& Louw-Potgieter, 2008; Meyers, 2007). It is presumed that I/O psychologists would experience their work as a calling, though there is no literature available to reference how these individuals view the meaning of their work.

The presence of psychological meaningfulness refers to the subjective sense that one's work is meaningful. Kahn (1990, p. 703-704) defines psychological meaningfulness as 'a feeling that one is receiving a return on investments of one's self in a currency of physical, cognitive, or emotional energy'. Psychological meaningfulness occurs when individuals feel useful and valuable and that they are making a difference (Kahn, 1990). Given that psychological meaningfulness reflects a sense of purpose or personal connection to work (Spreitzer, 1995), it is expected that individuals with a calling orientation to work will experience more meaning in their work than those with job or career orientations. Furthermore, employees who spend time on desired activities and who experience work-role fit will experience more psychological meaningfulness, which will contribute to higher levels of work engagement (May et al., 2004; Olivier \& Rothmann, 2007). It should be noted that although psychological meaningfulness is related to and has been shown to predict work engagement, it is also regarded as a separate construct (Peterson et al., 2005).

Work engagement has emerged as an important topic in positive I/O psychology in recent years (Macey \& Schneider, 2008; May et al., 2004; Schaufeli \& Bakker, 2004). Empirical research confirmed the relationship between engagement and organisational outcomes (e.g. organisational commitment, turnover intention, productivity, motivation, job resources and burnout) (e.g. Bakker, Demerouti \& Schaufeli, 2005; Hakanen, Bakker \& Schaufeli, 2006; Harter, Schmidt \& Hayes, 2002; Schaufeli \& Bakker, 2004). Theoretically, engagement is grounded in desire theory (Griffen, 1986; Sirgy \& Wu, 2009), which focuses on need gratification rather than the pursuit of pleasure to increase happiness. Gratification is enhanced by engaging in activities that generate flow experience (Csikszentmihalyi, 1999). However, the concept of flow focuses heavily on the cognitive component of engagement (i.e. absorption) and does not include the physical and emotional components thereof.

State engagement (which is relevant for this study) can be defined as the extension of oneself to a work role categorised by feelings of absorption, satisfaction, energy, commitment and involvement in one's work (Macey \& Schneider, 2008).
Engagement exists when one feels physically, emotionally and cognitively attached to a work role (May et al., 2004). The experience of the mentioned attachment to one's work is facilitated by the opportunity to apply one's signature strengths in a work situation (Peterson \& Seligman, 2004). This opportunity to express one's strengths leads to greater work-role fit, which leads to work engagement (May et al., 2004; Olivier \& Rothmann, 2007).

Schaufeli, Salanova, Gonzalez-Roma and Bakker (2002, p. 74) define work engagement as 'a positive, fulfilling, work-related state of mind that is characterised by vigour, dedication and absorption'. Vigour is characterised by high levels of energy and mental resilience while working. Dedication refers to being strongly involved in one's work and experiencing a sense of significance, enthusiasm, inspiration, pride and challenge. Absorption is characterised by being fully concentrated on and happily engrossed in one's work, whereby time passes quickly and one has difficulties with detaching oneself from work. The Utrecht Work Engagement Scale (UWES) was developed to measure the three components of work engagement (Schaufeli et al., 2002). Unfortunately, at least one UWES item (e.g. 'I find the work I do full of meaning and purpose') measures the psychological condition of meaningfulness, which might contribute to work engagement rather than the construct itself (see Kahn, 1990; May et al., 2004).

In the literature study, the constructs of work-role fit, meaningfulness (meaning of work and psychological meaningfulness) and work engagement as routes towards happiness have been defined and the relationships between them described. Figure 1 proposes a conceptual model of the relationships between these constructs, which will be used in this study.

Based on the problem statement and literature review, the following hypotheses were formulated:

$\mathrm{H}_{1}$ : $\quad$ Work-role fit predicts the experience of psychological meaningfulness and work engagement of $\mathrm{I} / \mathrm{O}$ psychologists in South Africa.

$\mathrm{H}_{2}$ : Work-role fit mediates the relationship between the meaning of work and psychological meaningfulness.

$\mathrm{H}_{3}$ : Work-role fit mediates the relationship between the meaning of work and work engagement.

$\mathrm{H}_{4}$ : Psychological meaningfulness mediates the relationship between work-role fit and work engagement.

\section{RESEARCH DESIGN}

\section{Research approach}

A survey design was used to reach the research objective (Shaughnessy, Zechmeister \& Zechmeister, 2003). A correlational approach was followed.

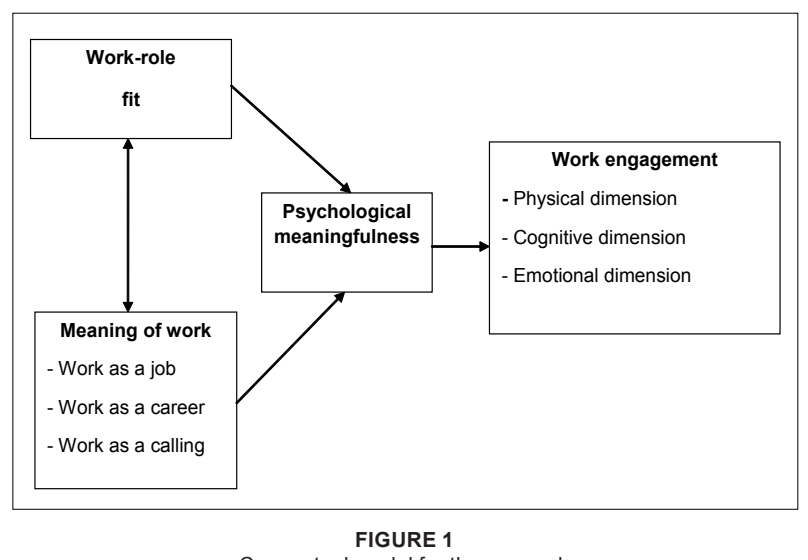

Conceptual model for the research 
TABLE 1

Characteristics of participants $(n=106)$

\begin{tabular}{|c|c|c|c|}
\hline Item & Category & Frequency & $\%$ \\
\hline \multirow[t]{2}{*}{ Gender } & Male & 48 & 45.30 \\
\hline & Female & 58 & 54.70 \\
\hline \multirow[t]{6}{*}{ Age } & $25-30$ years & 28 & 26.40 \\
\hline & $31-35$ years & 18 & 17.00 \\
\hline & $36-40$ years & 21 & 19.80 \\
\hline & $41-45$ years & 9 & 8.50 \\
\hline & $46-50$ years & 12 & 11.30 \\
\hline & 51 and older & 18 & 17.00 \\
\hline \multirow[t]{4}{*}{ Race } & White & 92 & 86.80 \\
\hline & African & 8 & 7.50 \\
\hline & Coloured & 4 & 3.80 \\
\hline & Indian & 2 & 1.90 \\
\hline \multirow[t]{6}{*}{ Language group } & Afrikaans & 71 & 67.00 \\
\hline & English & 30 & 28.30 \\
\hline & Xhosa & 1 & 0.90 \\
\hline & Zulu & 1 & 0.90 \\
\hline & Tsonga & 1 & 0.90 \\
\hline & South Sotho & 2 & 1.90 \\
\hline \multirow[t]{7}{*}{ Province } & Gauteng & 70 & 66.00 \\
\hline & Free State & 10 & 9.40 \\
\hline & Mpumalanga & 4 & 3.80 \\
\hline & North West & 10 & 9.40 \\
\hline & Northern Cape & 2 & 1.90 \\
\hline & Eastern Cape & 3 & 2.80 \\
\hline & Western Cape & 7 & 6.60 \\
\hline \multirow[t]{4}{*}{ Educational level } & Master's degree & 69 & 65.10 \\
\hline & Doctoral degree & 28 & 26.40 \\
\hline & Post-doctoral degree & 2 & 1.90 \\
\hline & Professoriate & 7 & 6.60 \\
\hline \multirow[t]{4}{*}{ Type of employment } & Higher education & 31 & 29.20 \\
\hline & Private sector & 48 & 45.30 \\
\hline & Public sector & 10 & 9.40 \\
\hline & Private consultation & 17 & 16.00 \\
\hline \multirow[t]{8}{*}{ Number of years registered } & $0-5$ years & 47 & 44.30 \\
\hline & $6-10$ years & 27 & 25.50 \\
\hline & $11-15$ years & 12 & 11.30 \\
\hline & $16-20$ years & 4 & 3.80 \\
\hline & $21-25$ years & 7 & 6.60 \\
\hline & $26-30$ years & 5 & 4.70 \\
\hline & $31-35$ years & 3 & 2.80 \\
\hline & 36 years and longer & 1 & 0.90 \\
\hline
\end{tabular}

\section{Research method}

\section{Participants}

An initial random sample $(n=300)$ was drawn, which produced a $1.3 \%$ response rate. Therefore, a convenience sample $(n=$ 106) was drawn from the entire population (1148) (response rate $=9.23 \%$ ). An electronic version of the questionnaire was emailed to participants. Table 1 provides an overview of the characteristics of the participants.

According to Table 1, the majority of the participants were Afrikaans-speaking (67\%), White (88.6\%) women (54.7\%) between the ages of 25 and $30(26.4 \%)$. The majority of the participants had been registered as I/O psychologists for $0-5$ years $(44.3 \%)$, were employed within Gauteng $(66 \%)$ and worked in the private sector (45.3\%). Most of the participants held a master's degree (65.1\%).

\section{Measuring battery}

The Work-Role Fit Scale (WRFS) (May et al., 2004) was used to measure work-role fit. Work-role fit is measured by averaging four items (e.g. 'My job "fits" how I see myself') that measure the perceived fit between individuals' jobs and self-concept. For all items, a five-point agreement-disagreement Likert scale varying from 1 (totally agree) to 5 (totally disagree) was used. Olivier and Rothmann (2007) confirmed the reliability of the WRFS in a petrochemical company $(a=0.90)$.

The Work-Life Questionnaire (WLQ) (Wrzesniewski et al., 1997) was utilised in order to determine the levels of meaning I/O psychologists associate with their work. According to Wrzesniewski et al. (1997), the WLQ is a self-report measure that aims to classify an individual's orientation to work into three main categories, namely, (1) work as a job, (2) work as a career and (3) work as a calling. The questionnaire is divided into two parts. The first part contains a set of three paragraphs representing the three main meanings of work, in which the respondent is encouraged to rate his or her level of association with each paragraph on a scale of 1 (very much like me) to 4 (not at all like me). The second part consists of a set of 18 items to substantiate the respondent's position on the first part of the questionnaire (e.g. 'My primary reason for working is financial.') The items are also rated on a Likert scale varying from 1 (very much like me) to 4 (not at all like me).

The Psychological Meaningfulness Scale (PMS) (Spreitzer, 1995) was used to measure psychological meaningfulness by averaging six items. For all items, an agreement-disagreement Likert scale varying from 1 (totally agree) to 5 (totally disagree) was used. These items measure the degree of meaning that individuals discovered in their work-related activities (e.g. 'The work I do on this job is very important to me.'). May et al. (2004) found a Cronbach alpha coefficient of 0.90 for the PMS in a large insurance company, while Olivier and Rothmann (2007) reported a Cronbach alpha coefficient of 0.92 for the PMS in a petrochemical company.

The Work Engagement Scale (WES) (May et al., 2004) was adapted and used to measure work engagement. For all items, a Likert scale varying from 1 (strongly agree) to 5 (strongly disagree) was used. The items reflect each of the three components of Kahn's (1990) conceptualisation of work engagement, namely cognitive ('Time passes quickly when I perform my job'), emotional ('I really put my heart into my job') and physical engagement ('I take work home to do'). Olivier and Rothmann (2007) found a one-factor engagement model within a petrochemical company consisting of cognitive, emotional and physical engagement ( $\alpha$ $=0.72$ ), which is consistent with findings by May et al. (2004) in a large insurance firm, where fewer items were used.

Finally, a self-developed Perceived Actual Time (PAT) questionnaire was used to determine the actual amount of time the participants spent on and the desired time the participants wanted to spend on six broad categories of work (see Benjamin \& Louw-Potgieter, 2008). Benjamin and LouwPotgieter (2008) state that I/O psychologists are actively engaging in, (1) psychological assessment, (2) therapy and counselling, (3) human resource management, (4) human resource administration, (5) training and development and (6) interventions and consultation. Based on this, participants were asked to indicate both their actual and desired time spent on these six broad categories of work.

\section{Procedure}

A cover letter explaining the purpose and emphasising the confidentiality of the research project accompanied the questionnaire. The researcher tried to make contact with the Society of Industrial and Organisational Psychology in South Africa (SIOPSA) in order to request access to its membership list; however, no response was received. The researcher 
made appointments with various leaders in the field of I/O psychology to introduce them to the topic and to secure their participation with regard to tracking down respondents. A list of all the registered I/O psychologists was obtained from the Health Professions Council of South Africa (HPCSA). Initially, a random sample of 300 was drawn with a response rate of $1.3 \%$. As an alternative, a convenience sample $(n=106)$ was drawn. In their study, Benjamin and Louw-Potgieter (2008) drew a sample of 129 respondents with full access to the SIOPSA's membership database. Participation in the project was voluntary and respondents had the option to withdraw at any time. During October through November 2009, emails were sent out to the respondents, inviting them to complete the questionnaire. The raw data were captured and converted to an SPSS dataset.

\section{Statistical analysis}

The statistical analysis was carried out with the SPSS program (SPSS Inc., 2009). Descriptive statistics were used to analyse the data. Exploratory factor analyses and Cronbach's alphas were used to determine the construct validity and reliability of the measuring instruments. Pearson correlation coefficients were used to specify the relationships between the variables. The cut-off point for statistical significance was set at $p<0.01$. Effect sizes were used to decide on the practical significance of findings (Steyn, 1999). A cut-off point of 0.30 (medium effect) was set for the practical significance of correlation coefficients (Cohen, 1992).

Canonical correlation was used to determine the relationships between the constructs. The goal of canonical correlation is to analyse the relationship between two sets of variables (Tabachnick \& Fidell, 2001). Multiple regression analyses were used in order to investigate whether work-role fit and meaning of work predict psychological meaningfulness and whether all these variables predict engagement.

\section{RESULTS}

\section{Exploratory factor analyses}

Exploratory factor analyses were undertaken to investigate the underlying factor structure of the measuring instruments. First, principal component analyses were used to assess the factorability of the items of the various scales and to determine the number of factors in each scale. Eigenvalues $(>1)$ and the scree plot were used to determine the number of factors in each scale. Second, a principal axis factor analysis with a direct oblimin rotation was used in cases where scales had more than two factors or more.

A principal component analysis was conducted on the four items of the WRFS. The Kaiser-Meyer-Olkin measure of sampling adequacy revealed a value of 0.75 , which indicated that the items were factorable. Bartlett's test of sphericity showed to be highly significant $\left(\chi^{2}(6)=183.30 ; p<0.05\right)$. The scale produced communalities that were all higher than the suggested 0.30. A principal component analysis showed that one factor (eigenvalue $=2.76$ ) could be extracted . The component loadings ranged from 0.79 to 0.88 . The factor (labelled work-role fit) explained $69.05 \%$ of the total variance of the scale.

A principal component analysis was conducted on the 21 items of the WLQ. The Kaiser-Meyer-Olkin measure of sampling adequacy revealed a value of 0.74 , which indicated that the items were factorable. Bartlett's test of sphericity showed to be highly significant $\left(\chi^{2}(210)=933.49 ; p<0.05\right)$. The scale produced communalities that were all higher than the suggested 0.30 . The scree plot indicated that two factors (with eigenvalues of 5.73 and 2.51 respectively) could be extracted. Factor 1 and Factor 2 explained $30.18 \%$ and $13.21 \%$ of the total variance, respectively. Factor 1 represented the job/calling orientation to work, whereas Factor 2 represented the career orientation. A third factor was proposed by Wrzesniewski et al. (1997), namely a job orientation. Wrzesniewski et al. (1997) proposed work as a job and work as a calling to be on a continuum. Items related to a calling orientation to work were reverse coded for the purposes of creating a job/calling orientation to work. Therefore, a high score on the dimension indicated a calling orientation to work, while a low score indicated a job orientation.

A principal component analysis was conducted on the five items of the PMS. The Kaiser-Meyer-Olkin measure of sampling adequacy revealed a value of 0.86 , which indicated that the items were factorable. Bartlett's test of sphericity showed to be highly significant $\left(\chi^{2}(10)=244.43 ; p<0.05\right)$. The scale produced communalities that were all higher than the suggested 0.30 . Only one factor had an eigenvalue larger than one (eigenvalue $=3.33$ ). The factor explained $66.68 \%$ of the total variance of the scale. The factor was labelled psychological meaningfulness.

A principal component analysis was conducted on the WES. In order to examine the factorability of the 17-item WES, a Kaiser-Meyer-Olkin measure of sampling and a Bartlett's test of sphericity were conducted. Firstly, the Kaiser-Meyer-Olkin measure of sampling adequacy revealed a 0.89 loading, which was well above Field's (2009) suggested 0.60. Secondly, Bartlett's test of sphericity showed to be highly significant $\left(\chi^{2}(136)=1\right.$ $260.77 ; p<0.05)$. The scale produced communalities that were all higher than the suggested 0.30, with the exception of three values. The principle component analysis proposed a onefactor model for work engagement, with an eigenvalue of 8.81 . Factor loadings ranging from 0.77 to 0.87 were present. The one-factor model explained $66.68 \%$ of the total variance of work engagement.

\section{Descriptive statistics and correlations}

The descriptive statistics (means, standard deviations and Cronbach alpha coefficients) and Pearson's correlations are reported in Table 2.

Table 2 shows that all five scales are sufficiently reliable $(\alpha$ $>0.70$ ), with alpha values varying from 0.80 to 0.93 (Nunnally \& Bernstein, 1994). The mean score on work-role fit (1.71) indicates a close relationship between the I/O psychologists' self-concept and the work in which they are engaged. The job/calling orientation to work (3.03) indicates that I/O psychologists view their work as a calling. The majority of the participants viewed their work as a calling (50\% in accordance with a frequency analysis). This implies that these participants feel that they are placed on earth to be I/O psychologists. A total of $16 \%$ of the respondents viewed their work as a career. These I/O psychologists work in order to move up in the organisation's hierarchy and they derive meaning from the social status and power associated with higher levels in the hierarchy. Finally, $6.6 \%$ of the participants viewed their work as a job. These individuals are only engaging in their work for financial reasons. It would seem that $\mathrm{I} / \mathrm{O}$ psychologists experience both psychological meaningfulness in their work (1.95) and work engagement (1.96).

Regarding the actual time spent on the six activities, the results showed the following mean percentages: psychological assessment $=20.29 \%(S D=22.79)$, therapy and counselling $=$ $12.48 \%(S D=11.51)$, HR management $=17.35 \%(S D=17.91)$, HR administration $=11.22 \%(S D=14.68)$, training and development $=18.07 \%(S D=20.26)$ and, interventions and consulting $=$ $19.80 \%(S D=16.80)$. Regarding the desired time spent on the six activities, the results showed the following mean percentages: psychological assessment $=21.65 \%(S D=18.54)$, therapy and counselling $=16.57 \%(S D=16.03)$, HR management $=13.03 \%$ $(S D=13.58), \mathrm{HR}$ administration $=5.96 \%(S D=9.38)$, training and development $=16.23 \%(S D=17.19)$ and, intervention and consulting $=26.28 \%(S D=17.20)$. 
TABLE 2

Descriptive statistics, alpha coefficients and Pearson correlations for work role fit, meaning of work, psychological meaningfulness and work engagement

\begin{tabular}{|c|c|c|c|c|c|c|c|c|c|c|c|c|c|}
\hline Item & Mean & $S D$ & $a$ & 1 & 2 & 3 & 4 & 5 & 6 & 7 & 8 & 9 & 10 \\
\hline 1. Work-Role fit & 1.71 & 0.62 & 0.87 & - & - & - & - & - & - & - & - & - & - \\
\hline 2. Psychological meaningfulness & 1.95 & 0.78 & 0.85 & $0.89^{*++}$ & - & - & - & - & - & - & - & - & - \\
\hline 3. Work engagement & 1.96 & 0.63 & 0.93 & $0.74^{*++}$ & $0.70^{*++}$ & - & - & - & - & - & - & - & - \\
\hline 4. Job/Calling orientation to Work & 3.03 & 0.56 & 0.87 & $-0.74^{\star++}$ & $-0.69^{*++}$ & -0.08 & - & - & - & - & - & - & - \\
\hline 5. Career orientation to Work & 2.44 & 0.91 & 0.80 & $-0.41^{*+}$ & $-0.35^{*+}$ & $-0.19^{*}$ & $0.29^{*}$ & - & - & - & - & - & - \\
\hline 6. Difference: Psychological assessment & -1.36 & 13.95 & - & -0.11 & -0.04 & 0.19 & -0.10 & 0.05 & - & - & - & - & - \\
\hline 7. Difference: Thearpy/Counselling & -4.08 & 14.35 & - & -0.15 & $-0.25^{\star}$ & $0.27^{*}$ & 0.13 & 0.03 & 0.19 & - & - & - & - \\
\hline 8. Difference: HR Management & 4.32 & 12.52 & - & $0.23^{*}$ & $0.21^{*}$ & -0.17 & $-0.21^{*}$ & -0.16 & $-0.33^{*+}$ & $-0.22^{*}$ & - & - & - \\
\hline 9. Difference: HR Administration & 5.25 & 9.95 & - & 0.14 & 0.16 & 0.03 & -0.08 & -0.10 & -0.19 & $-0.30^{*+}$ & 0.07 & - & - \\
\hline 10. Difference: Traning/Development & 1.84 & 11.06 & - & 0.05 & 0.12 & $-0.33^{\star+}$ & 0.11 & 0.16 & 0.00 & $-0.37^{\star+}$ & -0.24 & $-0.20^{*}$ & - \\
\hline 11. Difference: Intervention/Consultation & -6.49 & 13.16 & - & -0.18 & -0.15 & $-0.75^{\star++}$ & 0.15 & -0.02 & $-0.26^{*}$ & 0.09 & $-0.26^{*}$ & -0.14 & -0.12 \\
\hline
\end{tabular}

Note: Time Difference $=$ Actual time spending - Desired time spending

${ }^{*} p<0.05$ - statistacally significant; ${ }^{*} r>0.30$ - practically significant (medium effect); ${ }^{++} r>0.50$ - pratically significant (large effect)

I/O psychologists want to spend more time on psychological assessment (-1.36), therapy and counselling (-4.08) and, interventions and consulting (-6.49). They want to spend less time on HR management (4.32), HR administration (5.25) and, training and development (1.84). It seems that I/O psychologists want to spend less time on human resource activities than those relating to psychology. The mean scores on work-role fit (1.71) indicate a good relation between the self-concepts and the work I/O psychologists do.

The following statistically and practically significan correlations were found: work-role fit and psychological meaningfulness $(r=0.89 ; p<0.05$; large effect) and, work-role fit and work engagement $(r=0.74 ; p<0.05$; large effect). Therefore, Hypothesis 1 is accepted. Furthermore, the following correlation was found: work-role fit and job/calling orientation to work $(r=-0.74 ; p<0.05$; large effect). Psychological meaningfulness and work engagement correlated statistically and practically significantly $(r=0.70 ; p<0.05$; large effect). Psychological meaningfulness correlated statistically and practically significantly negatively with a job/calling orientation to work $(r=-0.69 ; p<0.05$; large effect). Work engagement correlated statistically significantly negatively with the discrepancy between actual and desired time on interventions and consultations $(r=-0.75 ; p<0.05$; large effect).

Work-role fit correlated statistically and practically significantly with a career orientation towards work $(r=0.41$

TABLE 3

Results of the canonical analysis: Work activities, meaning of work and work-role fit

First canonical variate

\begin{tabular}{lcc}
\cline { 2 - 3 } & Correlation & Coefficient \\
\hline Antecedents set & -0.56 & -1.51 \\
Difference: psychological assessment & -0.19 & -1.15 \\
Difference: therapy/counselling & 0.11 & 0.97 \\
Difference: HR management & 0.19 & -0.6 \\
Difference: HR administration & 0.64 & -0.29 \\
Difference: training/development & -0.28 & -1.2 \\
Difference: intervention/consulting & 2.63 & - \\
Percent of variance & 14.89 & - \\
Redundancy & & \\
& & \\
Outcomes set & 0.53 & 1.52 \\
Work-role fit & 0.09 & 1.06 \\
Job/calling orientation to work & 0.19 & 0.52 \\
Career orientation to work & 10.87 & - \\
Percent of variance & 1.93 & - \\
Redundancy & 0.42 & - \\
Canonical correlation & &
\end{tabular}

$p<0.05$; medium effect). Psychological meaningfulness was statistically and practically significantly and negatively related to career orientation $(r=-0.35 ; p<0.05$; medium effect). Work engagement correlated statistically and practically significantly negatively with the discrepancy between actual and desired time spent on training and development $(r=-0.33 ; p<0.05$; medium effect). The discrepancy between actual and desired time spent on psychological assessment correlated statistically and practically significantly negatively with the discrepancy between actual and desired time spent on HR management $(r=-0.33 ; p<0.05 ;$ medium effect). The discrepancy between the actual and desired time spent on therapy and counselling correlated statistically and practically significantly negatively with HR administration activities $(r=-0.30 ; p<0.05$; medium effect). The discrepancy between the actual and desired time spent on therapy and counselling correlated statistically and practically significantly negatively with training and development $(r=-0.37 ; p<0.05$; medium effect).

\section{Multivariate statistics}

The relationship of the differences between actual and desired time spent on the six broad work activities, meaning of work (job/calling versus career) and work-role fit was tested with canonical analysis. Shown in Table 3 are correlations between the variables and canonical variates, standardised canonical variate coefficients, within-set variance accounted for by the canonical variates (per cent of variance), redundancies and canonical correlations.

The first canonical correlation is 0.42 (18\% overlapping variance). The other two canonical correlations are 0.31 and 0.19 , with all three canonical correlations included $F_{(18,274.84}$ $=1.91, p<0.01$. The second $F$-test $\left(\mathrm{F}_{(10,196)}=1.39, p>0.05\right)$ and third $F$-test $\left(\mathrm{F}_{(4,99)}=0.89, p>0.05\right)$ are not statistically significant. In line with the recommendation of Tabachnick and Fidell (2001), only canonical correlations higher than 0.30 are interpreted here. The first canonical variate accounted for the significant relationship between the two sets of variables.

With a cut-off correlation of 0.30 , the variables in the work categories set that correlate with the first canonical variate are difference: psychological assessment $(-0.56)$ and difference: training and development (0.64). Among the outcomes set, work-role fit (0.53) correlates with the first canonical variate.

Next, a series of multiple regression analyses were performed to test whether the work-role fit mediated the relationship between the meaning of work (i.e. job/calling and career) and psychological meaningfulness. Baron and Kenny 
TABLE 4

Regression analyses with meaning of work and work-role fit as independent variables and psychological meaningfulness as dependent variable

\begin{tabular}{|c|c|c|c|c|c|c|c|c|c|}
\hline \multirow[t]{2}{*}{ Model } & & \multicolumn{2}{|c|}{ Unstandardised Coefficients } & \multirow{2}{*}{$\begin{array}{c}\text { Standardised Coefficients } \\
\text { Beta }\end{array}$} & \multirow[t]{2}{*}{$t$} & \multirow[t]{2}{*}{$p$} & \multirow[t]{2}{*}{$F$} & \multirow[t]{2}{*}{$R$} & \multirow[t]{2}{*}{$R^{2}$} \\
\hline & & B & SE & & & & & & \\
\hline \multirow[t]{4}{*}{ Step 1} & & & & & - & - & $50.66^{*}$ & 0.70 & 0.49 \\
\hline & (Constant) & 19.909 & 1.22 & - & 16.30 & 0.00 & - & - & - \\
\hline & Job/calling orientation to work & -0.24 & 0.03 & -0.64 & -8.70 & $0.00^{*}$ & - & - & - \\
\hline & Career orientation to work & -0.15 & 0.06 & -0.17 & -2.35 & $0.02^{*}$ & - & - & - \\
\hline
\end{tabular}

Step 2

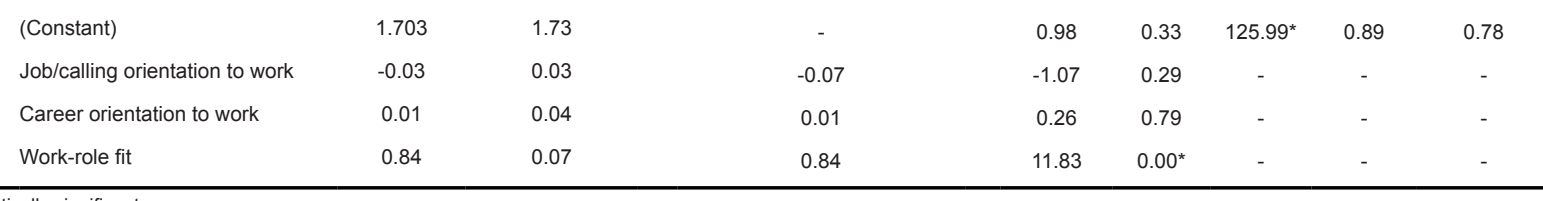

* $p<0.05$ - statistically significant

(1986) recommend three steps in order to test for mediation. According to these authors, beta coefficients of different regression equations must be compared. Firstly, the mediator should be predicted by the independent variable. Secondly, the dependent variable should be predicted by the mediator and the independent variable. Lastly, the dependent variable should be regressed on the independent variable, controlling for the mediator. If all steps prove significant, perfect mediation holds when, controlling for the mediator, the independent variable does not predict the dependent variable.

Firstly, to test whether work-role fit is predicted by the meaning of work, a multiple regression analysis was carried out with work-role fit (as measured by the WRFS) as dependent variable and the meaning of work (as measured by the WLQ) as independent variable. The results showed that the meaning of work (i.e. job/calling orientation predicted $59 \%$ of the variance in work-role fit $\left(F_{(2,103)}=72.71, p<0.01\right)$. The beta coefficients of the job/calling orientation to work $(\beta=-0.67, p<0.01)$ and the career orientation $(\beta=-0.22, p<0.01)$ were statistically significant. The first requirement for mediation was therefore satisfied.

Secondly, to test whether psychological meaningfulness is predicted by work-role fit, a multiple regression analysis was carried out with psychological meaningfulness (as measured by the PMS) as dependent variable and work-role fit (as measured by the WRFS) as independent variable. The results showed that work-role fit predicted $79 \%$ of the variance in psychological meaningfulness $\left(F_{(1,104)}=379.60, p<0.01\right)$. The beta coefficient of work-role fit was statistically significant $(\beta=0.89, p<0.01)$. Furthermore, Table 4 shows the results of a multiple regression analysis with psychological meaningfulness (as measured by the PMS) as dependent variable and meaning of work (as measured by the WLQ) in step 1 and work-role fit (as measured by the WRFS) in step 2 as independent variables.
Table 4 shows that meaning of work (job/career and calling) predicted $49 \%$ of the variance in psychological meaningfulness $\left(F_{(2,103)}=50.66, p<0.01\right)$. The beta coefficients of job/calling orientation and career orientation were statistically significant $(\beta=0.89, p<0.01)$. Therefore, the second condition for mediation was satisfied. Table 4 also shows that the independent variables (job/calling orientation and career orientation) and mediator (work-role fit) predicted $78 \%$ of the variance in psychological meaningfulness $\left(F_{(3,102)}=125.99, p<0.01\right)$. However, only the beta coefficient of the work-role fit was statistically significant in the last step of the regression analysis $(\beta=0.84, p<0.01)$. It can be concluded that work-role fit mediated the relationship between meaning of work and psychological meaningfulness. Therefore, Hypothesis 2 is accepted.

A multiple regression analysis with work engagement (as measured by the WES) as a dependent variable and work-role fit (as measured by the WRFS), job/calling orientation and career orientation (as measured by the WLQ) and psychological meaningfulness (as measured by the PMS) as independent variables was subsequently carried out. The results showed that work-role fit, meaning of work and psychological meaningfulness predicted work engagement statistically significantly $\left(F_{(4,100)}=45.08, p<0.01 ; R^{2}=0.64\right)$. Only the beta coefficient of job/calling orientation to work was statistically significantly in the model $(\beta=-0.45, p<0.01)$. Psychological meaningfulness was not a statistically significant predictor when it was entered into the regression model $\left(\Delta F_{(1,100)}=1.26\right.$, $p>0.05)$.

Next, a series of multiple regression analyses was performed to test whether work-role fit mediated the relationship between meaning of work (i.e. job/calling and career) and work engagement. Firstly, the previous results already showed that work-role fit was predicted by meaning of work.

TABLE 5

Regression analyses with meaning of work and work-role fit as independent variables and work engagement as dependent variable

\begin{tabular}{|c|c|c|c|c|c|c|c|c|c|}
\hline \multirow[t]{2}{*}{ Model } & & \multicolumn{2}{|c|}{ Unstandardised Coefficients } & \multirow{2}{*}{$\frac{\text { Standardised Coefficients }}{\text { Beta }}$} & \multirow[t]{2}{*}{$t$} & \multirow[t]{2}{*}{$p$} & \multirow[t]{2}{*}{$F$} & \multirow[t]{2}{*}{$R$} & \multirow[t]{2}{*}{$R^{2}$} \\
\hline & & B & SE & & & & & & \\
\hline \multirow[t]{4}{*}{ Step 1} & & & & & - & - & $69.75^{*}$ & 0.76 & 0.58 \\
\hline & (Constant) & 78.16 & 3.87 & - & 20.21 & 0.00 & - & - & - \\
\hline & Job/calling orientation to work & -0.91 & 0.09 & -0.72 & -10.66 & $0.00^{*}$ & - & - & - \\
\hline & Career orientation to work & -0.35 & 0.20 & -0.12 & -1.78 & 0.08 & - & - & - \\
\hline \multicolumn{10}{|l|}{ Step 2} \\
\hline & (Constant) & 48.56 & 8.01 & - & 6.06 & 0.00 & $59.52^{*}$ & 0.80 & 0.64 \\
\hline & Job/calling orientation to work & -0.58 & 0.11 & -0.45 & -5.07 & $0.00^{*}$ & - & - & - \\
\hline & Career orientation to work & -0.08 & 0.20 & -0.03 & -0.41 & 0.68 & - & - & - \\
\hline & Work-role fit & 1.38 & 0.33 & 0.39 & 4.13 & $0.00^{*}$ & - & - & - \\
\hline
\end{tabular}


Secondly, to test whether work engagement was predicted by work-role fit, a multiple regression analysis was carried out with work engagement as dependent variable and work-role fit as independent variable. The results showed that workrole fit predicted $55 \%$ of the variance in work engagement $\left(F_{(1,103)}=124.26, p<0.01\right)$. The beta coefficient of work-role fit was statistically significant $(\beta=0.74, p<0.01)$. Furthermore, Table 5 shows the results of a multiple regression analysis with work engagement as dependent variable and meaning of work in step 1 and work-role fit in step 2 as independent variables.

Table 5 shows that meaning of work (job/career and calling) predicted $58 \%$ of the variance in work engagement $\left(F_{(2,102)}\right.$ $=69.75, p<0.01)$. The beta coefficient of job/calling orientation to work was statistically significant $(\beta=-0.72, p<0.01)$. Therefore, the second condition for mediation was satisfied. Table 5 also shows that the independent variables (job/calling orientation and career orientation) and mediator (work-role fit) predicted $80 \%$ of the variance in work engagement $\left(F_{(3,11)}=59.52, p<0.01\right)$. The beta coefficients of job/calling orientation $(\beta=-0.45, p$ $<0.01)$ and work-role fit $(\beta=0.39, p<0.01)$ were statistically significant in the last step of the regression analysis. It can be concluded that work-role fit mediated the relationship between meaning of work and work engagement. Therefore, Hypothesis 3 is accepted.

A final set of multiple regressions was performed to test whether psychological meaningfulness mediated the relationship between work-role fit and work engagement. Work-role fit predicted $54.7 \%$ of the total variance in work engagement $(F=124.26 ; p<0.01)$. The results indicated that work-role fit $(\beta=-0.74, p<0.01)$ was a statistically significant predictor of work engagement in step 1 . Although work-role fit was a statistically significant predictor of work engagement, work-role fit remained significant when psychological meaningfulness was entered into the regression. Therefore, psychological meaningfulness did not mediate the relationship between work-role fit and work engagement in a sample of I/O psychologists. Therefore, Hypothesis 4 is rejected.

\section{DISCUSSION}

The aim of this study was to investigate the relationships between the experiences of work-role fit, meaningfulness and work engagement of I/O psychologists in South Africa. Exploratory factor analyses and alpha coefficients indicated that all the constructs used in this study were valid and reliable. The results showed that the majority of the I/O psychologists view their work as a calling. I/O psychologists want to spend less time on activities relating to the field of human resource management and administration, and more time on psychological assessment, counselling and intervention. Work-role fit mediated the relationship between a calling orientation to work and psychological meaningfulness. Workrole fit partially mediated the relationship between a calling orientation to work and work engagement.

Exploratory factor analyses showed a one-factor model for work-role fit and psychological meaningfulness, which is in line with the findings of May et al. (2004), as well as those of Olivier and Rothmann (2007). Furthermore, a two-factor model for meaning of work was found. The first factor represented a job and calling orientation to work on a continuum, while the second factor structure produced the career orientation (Wrzesniewski et al., 1997). The three-factor structure of work engagement was not confirmed. The WES produced a one-factor model for total work engagement. This implies that people who are emotionally, cognitively and physically involved in their work experience work engagement. This is in line with the findings of Olivier and Rothmann (2007) and Van der Colff (2006), who also found a one-factor model of work engagement. All the questionnaires produced high Cronbach alpha values ranging from 0.80 to 0.93 . This implies that the surveys used were reliable in the sample of $\mathrm{I} / \mathrm{O}$ psychologists.

The results showed that I/O psychologists experience high levels of work-role fit. This implies that the respondents perceived a direct correlation between their self-concepts and the work they were engaging in. There are at least two explanations for the high scores obtained by I/O psychologists on work-role fit. Firstly, I/O psychologists are carefully selected before their honours and master's studies. Secondly, before registering as $\mathrm{I} / \mathrm{O}$ psychologist, candidates have to complete a 12-month internship and pass the HPCSA's board examination in I/O psychology. These selection and socialisation activities probably increase I/O psychologists' eventual work-role fit (LeBon, 2001).

Despite the high scores on work-role fit, the results showed that I/O psychologists spend a large proportion of their time on human resource activities (including human resource management, human resource administration and training and development). It was found that I/O psychologists wish to spend more time on those activities relating to I/O psychology (including psychological assessment, therapy and counselling and, interventions and consultation) and less time on activities relating to human resource management.

A discrepancy was found between the actual and desired time $\mathrm{I} / \mathrm{O}$ psychologists spend on their work activities. On average, I/O psychologists spend their time (arranged from highest to lowest percentage) on psychological assessment (20.29\%), training and development (18.07\%), human resource management $(17.35 \%)$ intervention and consulting (16.57\%), therapy and counselling (12.48\%) and, human resource administration (11.22\%) However, on average, they would like to spend their time (arranged from highest to lowest percentage) on intervention and consulting (26.28\%), psychological assessment (21.65\%) therapy and counselling (16.7\%), training and development $(16.23 \%)$, human resource management (13.03\%) and human resource administration (5.96\%). It is interesting to note that I/O psychologists spend about $29 \%$ of their time on human resource management and administration, while they would like to spend only $19 \%$ of their time on these activities. In contrast, Benjamin and Louw-Potgieter (2008) found that I/O psychologists spend (arranged from highest to lowest percentage) $34 \%$ of their time on intervention and consulting activities, $22 \%$ on psychological assessment, $12 \%$ on human resource management activities, $12 \%$ on human resource administration, $9 \%$ on training and development, and $6 \%$ on therapy and counselling (6\%). These findings are substantiated by Barnard and Fourie (2007), who state that I/O psychologists want to spend more time on activities relating to pure psychology. The canonical analysis showed that higher workrole fit was experienced by I/O psychologists who spend more time on training and development than they would like to, but who want to spend more time on psychological assessment than what they are currently spending.

The majority of the I/O psychologists viewed their work as a calling. I/O psychologists believe that their work contributes to a greater cause. This might be attributable to the fact that I/O psychologists spend most of their time engaging in the various social systems of the organisation. I/O psychologists facilitate the development from dysfunctional behaviour to 'normal' or optimal development (LeBon, 2001); the calling orientation to work might therefore be attributable to knowing that they have an impact on the lives of others. This is in line with the hypothesis of Bellah et al. (1985) that individuals in helping professions perceive their work as a calling. Furthermore, the $\mathrm{I} / \mathrm{O}$ psychologists experienced their work to be psychologically meaningful and showed high levels of work engagement.

The Pearson correlations in this study showed that workrole fit was strongly related to a calling orientation to work, psychological meaningfulness and work engagement. Work-role fit was moderately related to a career orientation. Psychological meaningfulness was also strongly related to a 
calling orientation to work and work engagement. Work-role fit, psychological meaningfulness and work engagement were moderately related to a career orientation. It is clear that there is a strong relationship between the calling orientation to work, psychological meaningfulness and work engagement. These findings are in line with the findings of Peterson et al. (2009) that psychological meaningfulness and work engagement (as the routes towards happiness) are facilitated by the experience of a calling in life. Similarly, work-role fit impacts on this relationship. When a person experiences work as a calling, it facilitates proximity between the self-concept and the work role. This inadvertently leads to the experience of psychological meaningfulness in work.

The results of this study confirm that work-role fit predicts psychological meaningfulness and work engagement. However, psychological meaningfulness did not mediate the relationship between work-role fit and work engagement, which is contrary to the findings of May et al. (2004) and Olivier and Rothmann (2007). This study made use of a correlational research design, which makes it impossible to prove causal relationships. However, to test the possible relationships between the variables, a regression analysis strategy was followed in which the effects of meaning of work and work-role fit (as independent variables) and psychological meaningfulness and work engagement (as dependent variables) were studied. This is in line with the findings of Peterson et al. (2005) that meaningfulness and engagement are separate components of happiness (eudaimonic well-being), which might or might not be related.

The results of our study showed that work-role fit predicts psychological meaningfulness (i.e. the experienced component of meaning). Therefore, if I/O psychologists perceive that they fit their work roles, they tend to experience more psychological meaningfulness at work. Participating in activities that are congruent with an individual's values (Waterman, 1993) and/or signature strengths (Peterson \& Seligman, 2004; Seligman, 2002) contributes to the experience of psychological meaningfulness. Also, a close proximity between an individual's self-concept and his or her work role induces psychological meaningfulness since the person is able to express his or her beliefs, values and principles openly (Kahn, 1990; May et al., 2004; Olivier \& Rothmann, 2007). Furthermore, a calling and career orientation towards work predicted both work-role fit and work engagement. The beta coefficients of a calling orientation to work and a career orientation were not statistically significant when these two variables were entered with work-role fit in the regression equation for work engagement. These findings provide evidence that work-role fit mediates the relationship between meaning of work (either a calling or a career orientation) and psychological meaningfulness. Therefore, work as a calling and work as a career affect psychological meaningfulness through their effects on work-role fit.

It is possible that work-role fit is affected by individuals' job recrafting efforts. Wrzesniewski and Dutton (2003) suggest that it is a central human tendency to adapt to the environment. Wrzesniewski (2003) states that when individuals derive little meaning from their work, they adapt by recrafting their jobs in such a way as to derive more meaning. These activities are usually outside of these individuals' job descriptions. The experience of the I/O psychologists' high levels of work-role fit is attributable to possible job recrafting (Wrzesniewski \& Dutton, 2003). Since there is such a large discrepancy between the actual and desired time spent on work activities, I/O psychologists need to pursue meaning from other sources within their occupation.

The second set of regression analyses indicated that work-role fit partially mediates the relationship between the job/calling orientation to work and work engagement. The results showed that a calling orientation to work had a strong effect on work engagement and that this could partially be attributed to its effect on work-role fit. However, it seems that having a calling orientation to work strongly impacts on beliefs regarding workrole fit and work engagement.

In conclusion, based on the results of this study, it is evident that I/O psychologists generally view their work as a calling, while some view their work as a career. I/O psychologists are spending more time than they desire on human resource management, administration, and training and development. I/O psychologists experience high levels of work-role fit, which could be attributed to efforts to select, train and develop them, as well as to job-recrafting efforts by themselves. A calling orientation to work seems to have a strong effect on of psychological meaningfulness, work-role fit and work engagement.

Based on these results, various recommendations can be made. Firstly, it is important to foster a calling orientation to work in I/O psychologists during their selection, training and socialisation. A calling orientation to work will contribute towards experiences of work-role fit, psychological meaningfulness and work engagement. Secondly, managers who use the services of I/O psychologists should be made aware of the value that they can add in organisations by spending more time on I/O psychological activities and less time on HR activities. This could result in higher levels of psychological meaningfulness, which should have an enormous impact on I/O psychologists' organisational commitment, turnover intention and performance. Through understanding the effects of workrole fit, the meaning of work, psychological meaningfulness and work engagement, a deeper level of understanding can be developed of the happiness of I/O psychologists.

A major limitation to this study is that the design is crosssectional. As a result, no causal relationships could be identified. Longitudinal studies could provide deeper insight into which activities provide deeper meaning and the reasons for engagement. It is also recommended that a random sampling technique be used to ensure the absence of bias. Another major limitation to this study relates to the respondents. The majority of the respondents experienced high levels of psychological meaningfulness and work engagement. It would seem that only respondents who are experiencing meaning and who are engaged completed the questionnaire. Furthermore, the work activities indicate the actual and desired time spent but do not signify the importance of these activities. Furthermore, if a cross-sectional design is used in the future, a more ideal distribution method should be identified in order to address sample size issues. In the current study, a response rate of less than $10 \%$ was obtained via the email distribution.

It is recommended that the role of psychological meaningfulness and work engagement as routes towards happiness be considered and investigated further. Future studies should focus on job recrafting as a means to induce happiness through psychological meaningfulness and work engagement (Parry, 2006; Wrzesniewski \& Dutton, 2003). Finally, the psychometric properties of both the WLQ and the WES should be further investigated. Items on the WLQ should be revisited and clearly defined.

\section{REFERENCES}

Bakker, A.B., Demerouti, E., \& Schaufeli, W.B. (2005). The crossover of burnout and work engagement among working couples. Human Relations, 58, 661-689.

Barnard, G., \& Fourie, L. (2007). Exploring the roles and contributions of industrial psychologists in South Africa against a multi-dimensional conceptual framework. South African Journal of Industrial Psychology, 33(2), 4553.

Baron, R.M., \& Kenny, D.A. (1986). The moderator-mediator variable distinction in social psychological research: Conceptual, strategic, and statistical considerations. Journal of Personality and Social Psychology, 51, 11731182. 
Bellah, R., Madsen, R., Sullivan, W., Swidler, A., \& Tipton, S. (1985). Habits of the heart: Individualism and commitment in American life. Berkeley: University of California Press.

Benjamin, J., \& Louw-Potgieter, J. (2008). Professional work and actual work: The case of I/O psychologists in South Africa. South African Journal of Psychology, 38, 116-135.

Berg, J.M., Dutton, J.E., \& Wrzesniewski, A. (2008). What is job crafting and why does it matter? Theory-to-practice briefing, Ross School of Business, University of Michigan. Retrieved May 15, 2010, from www.bus.umich.edu/Positive/POS-Teachingand-Learning/Job_Crafting-Theory_to_Practice-Aug_08. pdf

Cameron, S., Dutton, J., \& Quinn, R. (2003). Positive organizational scholarship: Foundations of a new discipline. San Francisco: Berrett-Koehler Publishers.

Carvalho, A. (2005). Meaning of work and life role salience in a South African context: A cross-cultural comparison. Unpublished master's dissertation, University of Johannesburg, South Africa.

Cohen, J. (1992). A power primer. Psychological Bulletin, 112, $155-159$.

Csikszentmihalyi, M. (1999). If we are so rich, why aren't we happy? American Psychologist, 54, 821-827.

Dik, B.J., \& Duffy, R.D. (2008). Calling and vocation at work: Definitions and prospects for research practice. The Counselling Psychologist, 8, 48-61.

Field, A. (2009). Discovering statistics using SPSS: And sex and drugs and rock ' $n$ ' roll (3rd edn.). London: Sage Publications.

Frankl, V. (1988). The will to meaning: Foundations and applications of logotherapy. New York: Meridian.

Griffin, J. (1986). Well-being: Its meaning, measurement, and moral importance. Oxford: Clarendon Press.

Hakanen, J.J., Bakker, A. \& Schaufeli, W.B. (2006). Burnout and engagement among teachers. Journal of School Psychology, 43, 495-513.

Harter, J.K., Schmidt, F.L., \& Hayes, T.L. (2002). Business-unitlevel relationship between employee satisfaction, employee engagement, and business outcomes: A meta-analysis. Journal of Applied Psychology, 87, 268-279.

HPCSA. (2009). Health Professions Council of South Africa. Retrieved April 1, 2009, from Scope of Practice: Industrial Psychology: http://www.hpcsa.co.za.

Kahn, W.A. (1990). Psychological conditions of personal engagement and disengagement at work. The Academy of Management Journal, 33, 692-724.

LeBon, T. (2001). Wise therapy: Philosophy for counsellors. London: Sage Publishers.

Lopper, J. (2007). Career change advice: Find career jobs or a calling. Retrieved April 4, 2009, from Suite101: http://www.suite101. com/profile.cfm/coachjerry.

Macey, W.H., \& Schneider, B. (2008). The meaning of employee engagement. Industrial and Organizational Psychology: Perspectives on Science and Practice, 1, 3-30.

May, D., Gilson, R., \& Harter, L. (2004). The psychological conditions of meaningfulness, safety and availability and the engagement of the human spirit at work. Journal of Occupational and Organizational Psychology, 77, 11-37.

Meyers, C. (2007). Industrial psychology. New York: Garnsey Press.

Nunnally, J.C., \& Bernstein, I.H. (1994). Psychometric theory (3rd edn.). New York: McGraw-Hill.

Olivier, A.L., \& Rothmann, S. (2007). Antecedents of work engagement in a multinational oil company. South African Journal of Industrial Psychology, 33(3), 49-56.

Parry, G. (2006). Re-crafting work: A model for workplace engagement and meaning. Unpublished master's dissertation, University of Pensylvania.

Peterson C., Park, N., \& Seligman, M.E. (2005). Orientations to happiness and life satisfaction: The full life versus the empty life. Journal of Happiness Studies, 6, 25-41.
Peterson, C., Park, N., Hall, N., \& Seligman, M. (2009). Zest and work. Journal of Organizational Behavior, 30, 161172.

Peterson, C., \& Seligman, M.E.P. (2004). Character strengths and virtues: A handbook and classification. New York: American Psychological Association.

Pratt, M.G., \& Ashforth, B.E. (2003). Fostering meaningfulness in working and at work. In K. Cameron, J.E. Dutton, \& R.E. Quinn (Eds.), Positive organizational scholarship, (pp. 309-327). San Francisco: Barrett-Koehler.

Ryan, R.M., \& Deci, E.L. (2001). On happiness and human potentials: A review of research on hedonic and eudaimonic well-being. Annual Review of Psychology, 52, $141-166$.

Schaufeli, W.B., \& Bakker, A.B. (2004). Job demands, job resources, and their relationship with burnout and engagement: A multi-sample study. Journal of Organizational Behavior, 25, 293-315.

Schaufeli, W.B., Salanova, M., Gonzalez-Roma, V., \& Bakker, A. (2002). The measurement of engagement and burnout: A confirmative analytic approach. Journal of Happiness Studies, 3, 71-92.

Seligman, M. (2002). Authentic happiness. New York: Free Press.

Seligman, M.E.P. (2008). Positive health. Applied Psychology: An International Review, 57, 3-18.

Seligman, M.E.P., Parks, A., \& Steen, T. (2004). A balanced psychology and a full life. The Royal Society, Philosophical Transactions: Biological Sciences, 359, 1379_ 1381.

Shaughnessy, J.J., Zechmeister, E.B., \& Zechmeister, J.S. (2003). Research methods in psychology. (6th edn.). New York: McGraw-Hill.

Sirgy, M.J., \& Wu, J. (2009). The pleasant life, the engaged life, and the meaningful life: What about the balanced life? Journal of Happiness Studies, 10, 183-196.

Spreitzer, G. (1995). Psychological empowerment in the work place: Dimensions, measurement, and validation. Academy of Management Journal, 38, 1442-1465.

SPSS Inc. (2008). SPSS 17.0 for Windows. Chicago: SPSS Inc.

Steyn, H.S. (1999). Praktiese betekenisvolheid: Die gebruik van effek groottes. [Practical significance: The use of effect sizes]. Wetenskaplike bydraes - Reeks B: Natuurwetenskappe Nr. 117. Potchefstroom: Potchefstroomse Universiteit vir Christelike Hoër Onderwys (nou Noordwes Universiteit).

Tabachnick, B.G., \& Fidell, L.S. (2001). Using multivariate statistics (4th edn.). Boston: Allyn \& Bacon.

Van der Colff, J.J. (2006). Work-related well-being of registered nurses in South Africa. Unpublished doctoral thesis, North-West University, Potchefstroom, South Africa.

Waterman, A.S. (1993). Two conceptions of happiness: Contrasts of personal expressiveness (eudaimonia) and hedonic enjoyment. Journal of Personality and Social Psychology, 64, 678-691.

Wrzesniewski, A. (2003). Finding positive meaning at work. In K. Cameron, J.E. Dutton, \& R.E. Quinn (Eds.), Positive organizational scholarship, (pp. 296-308). San Francisco: Berrett-Koehler.

Wrzesniewski, A., \& Dutton, J.E. (2001). Crafting a job: Revisioning employees as active crafters of their work. Academy of Management Review, 26, 179-201.

Wrzesniewski, A., Dutton, J., \& Debebe, G. (2003). Interpersonal sense making and the meaning of work. Research in Organizational Behavior, 25, 95-135.

Wrzesniewski, A., McCauley, C., Rozin, P., \& Schwartz, B. (1997). Jobs, careers and callings: People's relations to their work. Journal of Research in Personality, 31, 21-33.

Wrzesniewski, A., \& Tosti, J. (2005). Career as a calling. In J.H. Greenhaus \& G.A. Callanan (Eds.), Encyclopaedia of career development Vol. 1, (pp. 71-75). Thousand Oaks: Sage Publications. 